\title{
Wireless Sensor Network and Monitoring of Crop Field
}

\author{
Joshi P $\mathrm{P}^{1}$, Dr.Kanade $\mathrm{S} \mathrm{S} \mathrm{S}^{2}$, Dr.Joshi S $\mathrm{P}^{3}$ \\ ${ }^{I}$ (Electronics \& Telecommunication Engineering, TPCT's College of Engineering, Osmanabad, India) \\ ${ }^{2}$ (Electronics \& Telecommunication Engineering, TPCT's College of Engineering, Osmanabad, India) \\ ${ }^{3}$ (Mechanical Engineering, JSPM's ICOER, Pune, India)
}

\begin{abstract}
This paper focuses on literature of the development of a wireless sensor network on agricultural environment to monitor environmental conditions and deduce the appropriate environmental parameters required for the high yield of crop production on a given farmland. Among the different technologies for crop monitoring, Wireless Sensor Networks (WSNs) are recognized as a powerful one to collect and process data in the agricultural domain with low-cost and low-energy consumption. Agriculture and farming is one of the industries which have recently diverted their attention to WSN, seeking this cost effective technology to improve its production and enhance agriculture yield standard. Wireless Sensor Networks (WSNs) have attracted much attention in recent years.
\end{abstract}

Keywords: Wireless Sensor Network, Precision Agriculture, Environmental Monitoring

\section{Introduction}

Sensor networks are used for collecting, storing and sharing the sensed data. They can also be defined as a system comprised of a set of sensor nodes and a communication system that allows automatic data collection and sharing. They allow monitoring remote, hazardous, dangerous or unwired areas. Factors such as the diversity of conditions which vary depending on location combined with the inability to predict the future characteristics of the environment during the different seasons over time complicate the decision making process and require specialized knowledge. Automation in agriculture brings about a fundamental contribution to what is now known as precision agriculture (or precision farming). In recent time, the wireless sensor network technology has found its implementation in precision agriculture as a result of the need for high productivity A definition of precision agriculture may be the following: the technique of applying the right amount of input (water, fertilizer, pesticide, etc.) at the right location and at the right time to enhance production and improve quality, while protecting the environment. This paper focuses on the development of a wireless sensor network on agricultural environment to monitor environmental conditions and deduce the appropriate environmental parameters required for the high yield of crop production on a given agriculture land. It is expected that such decisions will benefit both farming and irrigation by saving time and resources $[1,2,3]$.

\section{Literature Review}

Literature review is vital to have an in depth knowledge of one's intended research area and to learn more about subject matter. Importance of carry out a literature review is to identify research area, review state of the art and learn the area that needs further investigation or contribution. Purpose of this literature review is to know more about the study area of the topic which we are going to research and to learn from previous works done by other researchers in the area.

\subsection{Evolution of Wireless Sensor Networks}

Sensor networks were developed by the United States during the Cold War to detect and track Soviet submarines. A system of acoustic sensors called the Sound Surveillance System (SOSUS) was placed at strategic locations on the bottom of the ocean. Around the same time the United States also deployed a network of radars for air defense. These sensor networks had a hierarchical architecture and they were in fact wired sensor networks. They were not fully automated, human operators played an important role in maintaining the network. A wireless sensor network was introduced by the Defense Advanced Research Projects Agency (DARPA) in the early 1980's. It was called the Distributed Sensor Net- works (DSN) program where many lowcost sensing nodes were spatially distributed and they processed data collaboratively [4, 5]. By the mid 1980's the Massachusetts Institute of Technology (MIT) started developing a DSN to track low-ying aircrafts. Acoustic sensors such as microphones were arranged in the form of an array and were used for sensing. Mobile vehicles used as nodes processed the acoustic signals. It consisted of a single computer running on three processors which was powered by a quite generator mounted on the back of the vehicle. The nodes used microwave radios for communication $[2,5,6,7]$. 
A wireless sensor network (WSN) consists of spatially distributed autonomous sensors to monitor physical or environmental conditions, such as temperature, sound, vibration, pressure, humidity, motion or pollutants and to cooperatively pass their data through the network to a main location. A wireless sensor network (WSN) is a network formed by a large number of sensor nodes where each node is equipped with a sensor to detect physical phenomena such as light, heat, pressure, etc. WSNs are regarded as a revolutionary information gathering method to build the information and communication system which will greatly improve the reliability and efficiency of infrastructure systems $[5,8,9,10]$.

\subsection{Use of WSN in Agriculture}

Wireless Sensor networks can be used for monitoring spatio-temporal changes in climate, hydrology, pressure, motion, soil moisture, plant eco-physiology, pests and reporting best options to the agriculturist. Having such information at regularly would be a big boon for him. In order to ward of the adverse conditions which challenge the agriculturists, automatic actuated devices can be used to control irrigation, fertigation and pest control. Irrigation management is also one of the important activities in precision agriculture. Microplitis Croceipes, a tiny parasitoid wasp, locates caterpillars attacking cotton plants by keying on a complex volatile organic cocktail emitted from the plant when attacked. Thus sensors capable of detecting this cocktail would result in early detection and mitigation of these attacks by highly selective pesticide applications or wasp introductions $[5,6,11]$

In precision agriculture (PA), various parameters including soil type and temperature vary dramatically from one region to the other; consequently, any irrigation system must be flexible to adapt to such variations. Off-the-shelf irrigation controllers are usually expensive and not effective in managing scarce water resources. On the other hand, an irrigation management system (IMS) based on wireless sensor networks (WSNs) can accept any desired irrigation scheduling strategy to meet specific environmental requirements. However, WSNs are still under a developmental stage; as such, they are at times unreliable, fragile, and power hungry and can easily lose communication especially when deployed in a harsh environment like an agricultural field [6, 12, 13]. Crop field monitoring is a crucial practice in agriculture to reduce resource waste and to increase yield in activities like irrigation and fertilization, because it allows farmers to access to solid information on the environmental, soil, and plant conditions and variations of their crops and make decisions from there. Although crop field monitoring have been made traditionally with human resources, single-point agrometeorological stations, and sensor wired networks, this topic immerse in precision agriculture demand a high density and flexible deployment of instrumentations to collect data in real time. WSNs have emerged to offer low-cost, flexible, easy-deployment, and high-accuracy advantages for crop monitoring in real time [8, 13].

\subsection{Structure of WSN}

Wireless Sensor Networks (WSN) emerged from advancements in the areas of micro-electromechanical system (MEMS) technology, wireless communication, and digital electronics. WSNs devices are small in size, low cost, and require low power to work. The basic structure of WSN sensor nodes is shown below (Figure 1). There are four main components that make up a sensor node. The parts are namely: a sensing unit, a processing unit, a transmission unit and a power unit. Depending on the type of application a sensor node may have additional parts such as a position finding system, mobilize and a power generator. Sensing unit usually takes the burden of sensing and gathering sensor data and then passes the data to the processing unit. The processing unit receives the sensed data and processes it according to a set procedure or program. A transmission unit connects the sensor not with a network. The power unit supplies power required to run a sensor node [1, 2, 17].

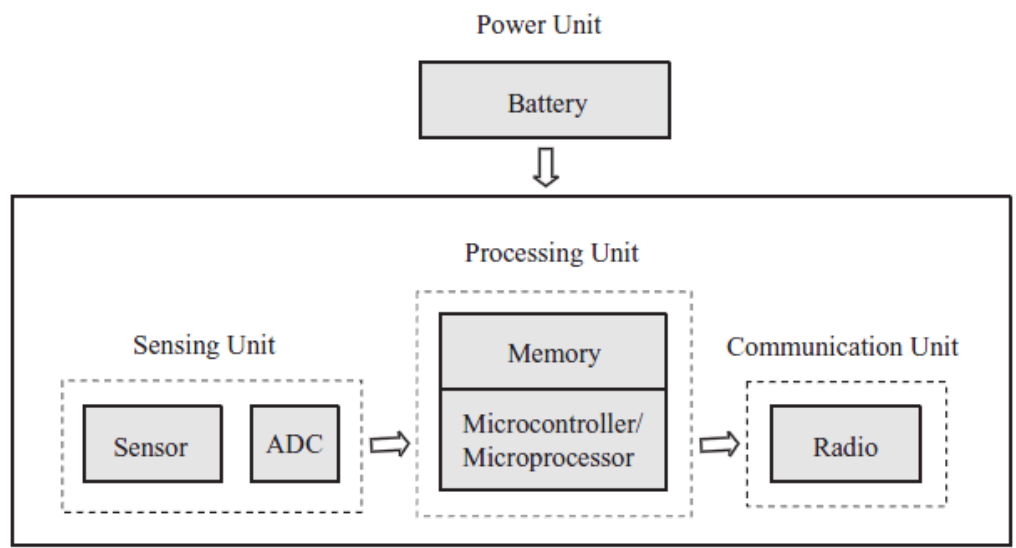

Figure 1 WSN Sensor Nodes General Structure 


\subsection{Characteristic Features of WSNs}

A WSN can generally be described as a network of nodes that cooperatively sense and control the environment, enabling interaction between persons or computers and the surrounding environment. WSNs nowadays usually include sensor nodes, actuator nodes, gateways and clients. A large number of sensor nodes deployed randomly inside of or near the monitoring area (sensor field), form networks through selforganization. Sensor nodes monitor the collected data to transmit along to other sensor nodes by hopping. During the process of transmission, monitored data may be handled by multiple nodes to get to gateway node after multihop routing, and finally reach the management node through the internet or satellite. It is the user who configures and manages the WSN with the management node, publish monitoring missions and collection of the monitored data $[8,14,18]$.

\subsection{WSN and Communication Technologies}

The term wireless refers to the communication or transmission of information over a distance without requiring wires, cables or any other electrical conductors. Wireless communication is one of the important mediums of transmission of data or information to other devices. In recent days, the wireless communication technology has become an integral part of several types of communication devices as it allows users to communicate even from remote areas. The devices used for wireless communication are cordless telephones, mobiles, GPS units, ZigBee technology, wireless computer parts, and satellite television, etc. A WSN is composed of several sensor nodes that have the capacity of sensing and gathering data. The sensor nodes can sense varying types of parameters and send it to a central gateway. WSN sensor and processing boards have the capability of working with various communication technologies. WSN can be linked to external servers or services both with wires or wirelessly (see Table 1: Connectivity options). Amongst others some of connection options could be using Ethernet connection, Wi-Fi, Bluetooth, or GSM-GPRS [15, 16, 17, 18].

Table 1 Connectivity Options

\begin{tabular}{|l|l|}
\hline Communication ways & Communication distance coverage \\
\hline Bluetooth & $30-100 \mathrm{~m}$ \\
\hline GPS-GPRS & Network carrier coverage $(\mathrm{km})$ \\
\hline Wi-Fi & $100-300 \mathrm{~m}$ \\
\hline ZigBee & $1-100 \mathrm{~m}$ \\
\hline
\end{tabular}

\subsection{Precision Agriculture}

Precision agriculture can be defined as the art and science of using advanced technology to enhance crop production. The term "precision agriculture" refers to a contemporary approach of applying new technologies utilizing sensors in order to optimize the agricultural cultivation processes. Wireless sensor network is a major technology that drives the development of precision agriculture. A precision agriculture method is where the amount of inputs (like seed, fertilizer, pesticides, water etc.) given to a specific farm field is important to control and monitor the condition of the farm to determine the amount of the crop output. The application of WSN in precision agriculture is one possible way to determine and control the inputs by monitoring the farm field for an improved and efficient precision irrigation. Sensor networks are used for integrating spatiotemporal patterns or trends in climate, hydrology, pressure, motion, soil moisture, metric potential, plant ecophysiology, pests, and reporting best management options to the agricultural manager $[5,18$, 19, 20]. In Precision-Agriculture field variations are monitored, stored for managing and maintaining the precious resources using technologies to manage and improve production or yield. This can be the tool at the hands of agriculturists for management with goal of optimizing return on investments while preserving natural resources. Precision Agriculture deals and takes care of viz. three branches of science

1. Crop Science: Understanding needs of crops according to weather and managing resources like fertilizers.

2. Environmental Protection: Precision agriculture helps to reduce Carbon, Nitrogen and Methane emissions.

3. Using WSN in agriculture can help reduce wastage, preserve resources, and utilize them effectively resulting in improved efficiency, reduced efforts and boost economy [13, 18, 21, 22]

Precision Agriculture model consist of, Wireless sensors to assist for spatial data collection, irrigation control model, Arrangement for supplying information to farmers, Variable-rate technology model and Green house parameter control system. In spatial data collection, a mobile field data acquisition system is available to collect useful data for crop management. The system is consisted of, a data collection instrument, a manager vehicle, data collection and control systems on farm machines. This system can handle local field survey and collects data of soil water availability, biomass yield, soil compaction, soil fertility, leaf area index, leaf temperature, leaf chlorophyll content, local climate data, insect-disease-weed infestation, plant water status, and yield of grain etc. Precision agriculture-based system design principles are increasingly used in research projects and commercial products to provide solutions for crop status monitoring, water supply regulation for irrigation, fertilizer management, pest control, and automated harvesting. Such systems benefit the complete process by 
reducing cost through automation and saving time. Another significant feature that precision agriculture provides to farmers is the ability to prevent hazardous incidents and to proactively monitor their crops and the local environmental conditions. The effectiveness of precision agriculture is based on the analysis of accurate sets of measurements in soft real-time. Parameters such as the soil condition and humidity are aggregated and analyzed, in order to extract useful information that a farmer can use as a recommendation or guidance; or even to apply fully automated procedures to the crop cultivation process chain $[13,17,23,24]$.

\subsection{WSN Applications in Agriculture \\ It mainly includes environmental monitoring, agriculture water management and pest control 2.71 Environmental Monitoring}

It describes the processes and activities that need to take place to characterize and monitor the quality of the environment. The foundation of EM is the collection of data, which enables a better understanding of our natural surroundings to be gained by means of observation. Environmental Monitoring is not limited to the understanding of environments, but also includes monitoring for preservation reasons. The environmental parameters, such as temperature, humidity, water seepage of ground, etc. are the key factors of substations in electric networks. The manual inspection is still used in many substations in India. Such traditional method exposes evident disadvantages:

1) Time-consuming since the wide distribution of substations;

2) No timeliness of failure discovery;

3) Carelessness of inspectors [8, 13, 17].

EM plays a key-role to show the effects of human behavior on the environment and to disclose its limits. Typical applications, in addition to purely environmental science purposes, include the protection of water supplies, radioactive waste treatment, air pollution monitoring, natural resource protection, weather forecasting and enumeration and monitoring of species. Environmental Monitoring strives to determine the status of a changing environment by analyzing a representative sample of the environment. As such, data acquisition forms a major part of EM. The data acquisition system in use has to allow for the collection of representative samples, which includes concerns such as the intrusiveness of the measurement system itself, sampling accuracy or sample storage. In the last few years, the occurrences of natural Changes in atmosphere is a have been becoming the cause for the Fungus, Bacterial attacks on the agricultural. If such changes are not aware in time to us the precautions cannot be taken and there will be bad affect on the agricultural production. Thus it is necessary to monitor parameters like Humidity, Soil moisture, water level of land [17, 18, 25].

\subsection{Agricultural Water Management}

Water consumption around the globe has increased seven times in the course of the last century. The level of ground water is declining. It is know that 1.1 billion people across the world live without satisfactory access to clean water. This results in the death of roughly 2 million people per year due to lack of water related diseases. Political stability itself is at risk, as experts predict that upcoming conflicts are most probably about water resources. As water supplies became scarcer, there is the need to manage water consumption. Water consumption has increased dramatically in the past decade [3]. Water is a precious resource, it is also considered as a source of conflict among nations. World water commission reports estimates that water us-age will increase by one half over the next 25 years. The application of wireless sensor network (WSN) for a water irrigation control monitoring is composed of a number of sensor nodes with a networking capability that can be deployed for an ad hoc and continuous monitoring purpose. The parameters involved in the water reservation control such as the water level and motor movement of the gate controlling the flow of water will be measured in the real time by the sensors that send the data to the base station or control/ monitoring room. Precision irrigation is an important practice in water- saving agriculture cropping system, which allows producers to maximize their productivity while saving water. While the accurate irrigation amount is difficult to obtain as the impact factor was too much $[6,8,13,25]$.

The fresh water management is crucial for human being to survive the increased population which paves the high demand for food. Agriculture is the one which utilizes most of the fresh water, must be optimized in a best way to avoid the draining of natural resource. Many strategies are employed to save water such as drip; sprinkler irrigations. Irrigation is the application of water to the land soil. Agriculture is an industry that uses a lot of water. Water seems abundant on our planet; however, less than $1 \%$ of the world's liquid freshwater is available for human use and about $70 \%$ of it is used for irrigation. So it is important to minimize water loss. This has motivated studies on control of irrigation channels where water losses can be large. Automation in irrigation system generally consists of soil moisture sensor or water level sensor, a control system and irrigation system components. There are also several researches on soil moisture sensor based irrigation system. Water level sensors have application in irrigation water distribution and delivery system $[1,8,13]$. 


\subsection{Pest Management}

Pest detection and control is at least as old as agriculture because there has always been a need to keep crops free from pests. A number of techniques so far proposed for pest control in agriculture using wireless sensor network. Since agriculture is considered as one of the oldest occupational activity, pest management and control is then born. Farm people usually need to keep their crops free from harmful pests as possible for these creatures may damage their yields resulting to a poor harvest and poor food quality. So far, there are many feasible techniques proposed for pest control in agriculture using wireless sensor network. One of these techniques may include pest identification through physical characteristic detection. The system has a stored data regarding the physical attributes of pests, when such pest is detected, the system can easily know what type of pest it is and immediately suggest possible ways on how to manage the farm situation $[1,8,16,17]$.

Aside from the reduced yields mentioned lately, pests and diseases can also cause great economic loss to farmers through increased costs of pesticides and other control measures, thus if they are engaged in a for-profit agricultural business they will be having lower net income. Pest control can be classified as technological, nontechnological or an integrated solution $[17,18,24,25]$

\section{Conclusion}

A sensor network is an emerging field with increasing applications day by day. This paper presents a crop monitoring system based on wireless sensor network. IOT has important significance in promoting agricultural informationization. Wireless monitoring of field not only allows user to reduce the human power, but it also allows user to see accurate changes in it. It is cheaper in cost and consumes less power. In present day precision agriculture, more number of the parameters are required to monitor and control because of the large varieties of the crop at the same time. Use of is increasing day by day because of the development in WSN technology and its adaption by agriculture technology. In this situation, the wireless sensor network with additional hardware and software is an efficient solution for Precision Agriculture.

\section{References}

\section{Journal Papers:}

[1]. Oliveira, L. M., \& Rodrigues, J. J., Wireless Sensor Networks: A Survey on Environmental Monitoring. JCM, 6(2), 2011, 143-151.

[2]. Wang, N., Zhang, N., \& Wang, M., Wireless sensors in agriculture and food industry-Recent development and future perspective. Computers and electronics in agriculture, 50(1), 2006, 1-14.

[3]. Srbinovska, M., Gavrovski, C., Dimcev, V., Krkoleva, A., \& Borozan, V., Environmental parameters monitoring in precision agriculture using wireless sensor networks. Journal of Cleaner Production, 88(1), 2015, 297-307.

[4]. Akyildiz, I. F., Su, W., Sankarasubramaniam, Y., \& Cayirci, E., A survey on sensor networks, IEEE Communications magazine, 40(8), 2002, 102-114.

[5]. Abbasi, A. Z., Islam, N., \& Shaikh, Z. A., A review of wireless sensors and networks' applications in agriculture, Computer Standards \& Interfaces, 36(2), 2014, 263-270.

[6]. Kim, Y. D., Yang, Y. M., Kang, W. S., \& Kim, D. K., On the design of beacon based wireless sensor network for agricultural emergency monitoring systems. Computer standards \& interfaces, 36(2), 2014, 288-299.

[7]. Keshtgary, M., \& Deljoo, A., An efficient wireless sensor network for precision agriculture, Canadian Journal on Multimedia and Wireless Networks, 3(1), 2012, 1-5.

[8]. Benghanem, M., RETRACTED: A low cost wireless data acquisition system for weather station monitoring. Renewable Energy, 35(4), 2010, 862-872.

[9]. Manikandan, K., \& Rajaram, S., Automatic Monitoring System for a Precision Agriculture Based On Wireless Sensor Networks, International Journal of Science, Engineering and Computer Technology, 6(6), 2016, 208.

[10]. Ferentinos, K. P., Katsoulas, N., Tzounis, A., Bartzanas, T., \& Kittas, C., Wireless sensor networks for greenhouse climate and plant condition assessment, Biosystems Engineering, 153(1), 2017, 70-81.

[11]. Bogue, R., Sensors key to advances in precision agriculture. Sensor Review, 37(1), 2017, 1

[12]. Anisi, M. H., Abdul-Salaam, G., \& Abdullah, A. H., A survey of wireless sensor network approaches and their energy consumption for monitoring farm fields in precision agriculture. Precision Agriculture, 16(2), 2015, 216-238.

[13]. Mulla, D. J., Twenty five years of remote sensing in precision agriculture: Key advances and remaining knowledge gaps, Biosystems engineering, 114(4), 2013, 358-371.

[14]. Awasthi, A., \& Reddy, S. R. N., Monitoring for precision agriculture using wireless sensor network-a review, Global Journal of Computer Science and Technology, 13(7), 2013, 1.

[15]. Sakthipriya, N., An effective method for crop monitoring using wireless sensor network, Middle-East Journal of Scientific Research, 20(9), 2014, 1127-1132.

[16]. El-Kader, S. M. A., \& El-Basioni, B. M. M., Precision farming solution in Egypt using the wireless sensor network technology, Egyptian Informatics Journal, 14(3), 2013, 221-233.

[17]. Brinis, N., \& Saidane, L. A., Context Aware Wireless Sensor Network Suitable for Precision Agriculture, Wireless Sensor Network, $8(1), 2016,1$.

Theses:

[18]. Zografos, A. (2014), Wireless Sensor-based Agricultural Monitoring System.

Proceedings Papers:

[19]. Silva, A. R., \& Vuran, M. C,Integration of center pivot systems with wireless underground sensor networks for autonomous precision agriculture, In Proceedings of the 1st ACM/IEEE International Conference on Cyber-Physical Systems,2010,79-88.

[20]. Kang, I., \& Poovendran, R., Maximizing static network lifetime of wireless broadcast ad hoc networks. In Communications, IEEE International Conference on, 2003, 2256-2261. 
[21]. Pereira, D. P., Dias, W. R. A., de Lima Braga, M., da Silva Barreto, R., Figueiredo, C. M. S., \& Brilhante, V., Model to integration of RFID into wireless sensor network for tracking and monitoring animals, In Computational Science and Engineering,11th IEEE International Conference on, 2008, 125-131.

[22]. Fazackerley, S., \& Lawrence, R., Reducing turfgrass water consumption using sensor nodes and an adaptive irrigation controller, In Sensors Applications Symposium (SAS), 2010, 90-94

[23]. Nguyen, L., \& Kodagoda, S., Soil Organic Matter Estimation in Precision Agriculture using Wireless Sensor Networks, In International Conference on Control, Automation, Robotics and Vision, IEEE, 2016, 1

[24]. Nandurkar, S. R., Thool, V. R., \& Thool, R. C., Design and development of precision agriculture system using wireless sensor network, In Automation, Control, Energy and Systems First International Conference on, 2014, 1-6

[25]. Kassim, M. R. M., Mat, I., \& Harun, A. N., Wireless Sensor Network in precision agriculture application. In Computer, Information and Telecommunication Systems (CITS) International Conference on, 2014, 1-5 